\title{
Remediation of Heavy Metals Contaminated Soils: A bibliometric Network Analysis
}

\author{
Rongxin Guo, Xusheng Zheng, Yiwen Yang, Dexun Zou, and Yanping Liu* \\ Department of Environmental Science and Engineering, Beijing University of Chemical Technology, Beijing, China
}

\begin{abstract}
With the acceleration of industrialization, heavy metal pollution, as one of the major types of soil pollution, is more and more serious. Therefore, the remediation of heavy metal contaminated soil has become a hotspot. This study explored the global scientific literature on the remediation of heavy metal contaminated soils, and conducted statistical and bibliometric analysis of 5733 documents in the core collection of Web of Science. The topics searched are: "Soil", Heavy metal" and "Remediation". The relationship among keywords, authors, countries, and publications for the remediation of heavy metal contaminated soils were showed in the knowledge map. Furthermore, the research hotspot evolution path of soil heavy metal remediation, the research status and development trend of related remediation technologies were analyzed. These results visualize the research results through bibliometrics, examine the research in this field from the perspective of the knowledge graph, and provide references for future development.
\end{abstract}

Keywords

Heavy metal, Soil contamination, VOSviewer, Citespace, Bibliometrics

\section{Introduction}

As the precious material wealth of mankind and the basis for the survival of various animals and plants, soil is an important element in geographical environment. The content of various biochemical substances in the soil has an inseparable relationship with the growth and development of animals and plants. However, according to National Survey Bulletin of Soil Pollution Status published in 2014, the total excess rate of soil in China was $16.1 \%$, of which $82.8 \%$ was attributed to inorganic elements, such as $\mathrm{Cd}, \mathrm{Hg}$ and As [1]. These metals will enter and accumulate in the bodies of animals by food chain and bioaccumulation. When the concentrations of heavy metals in soil exceed safety standards, they will cause serious adverse effects on the normal growth development of plants [2], even endangers the health of the animals.

Relevant research on heavy metals in soil, whether on innovation and optimization of remediation technologies, or on the forms and migration of heavy metals in soil, has achieved great progress in recent decades. At present, there are various remediation technologies used widely in heavy metals contaminated soil, including immobilization/ stabilization, soil leaching [3], phytoremediation [4], and microbial remediation [5]. Many scholars have reviewed and summarized the remediation technologies of heavy metals in the soil $[6,7]$ but there are few reports on the overall review based on bibliometric methods.

In this paper, the WOS database was used to conduct statistical analysis on the remediation of heavy metals in the soil. And bibliometric analysis methods, combining two bibliometric analysis software, CiteSpace and VOSviewer, Tableau visualization software, and SPSS statistical software were used for visual analysis and statistical analysis. By visualization methods, the global status and development trend of soil heavy metal remediation research were presented, which provided a certain reference for the research in this field.

\section{Data Sources and Statistical Methods}

\section{Data sources}

The data comes from the core collection in the Web of Science (WOS) database. The subject was the search item, the search conditions were "Soil", "Heavy metal" and "Remediation", and the search time range was from 2001 to 2020 , which was automatically set by the Web of Science

*Corresponding author: Yanping Liu, Department of Environmental Science and Engineering, Beijing University of Chemical Technology, Beijing 100029, China, Tel: +8613552445328

Accepted: July 22, 2021

Published online: July 24, 2021

Citation: Guo R, Zheng X, Yang Y, et al. (2021) Remediation of Heavy Metals Contaminated Soils: A bibliometric Network Analysis. J Soil Water Sci 5(2):205-217 
database. The number of obtained search results was 5733 . All data were saved as "plain text" files, which contain "complete records" and "complete records and cited references" and the deadline was May 20, 2020.

\section{Statistical methods}

SPSS was used to analyze the trend of the number of publications on soil heavy metal pollution remediation, and the Holt model in time series analysis was used to predict the number of publications in the next year. At the same time, Tableau was used to analyze the country of posting visually. VOSviewer was used to conduct clustering analysis on keywords and co-occurrence analysis on countries, authors and the citation of the article. CiteSpace was used to make statistics on publishing organizations and subject categories and analyze the strength of keywords. By forming a knowledge map, this study summarized and reviewed the global soil heavy metal remediation field.

\section{Results and Discussions}

\section{Literature types}

The samples obtained were classified and arranged. The document types of the 5733 articles retrieved were showed in Table 1 . There were 4897 research papers, which accounted for $85.418 \%$. Research papers represent the development trend and direction of this field to a certain degree.

\section{Publication trend}

To some extent, the number of articles published can reflect the degree of respect of this field. According to the search results, 5363 articles about soil heavy metal remediation were published from 2001 to 2019. As shown in Figure 1, since 2001, the number of articles on the remediation of soil heavy metal pollution has been increasing year by year and the growth rate has gradually increased. Time series analysis by SPSS predicted that the number of articles published throughout 2020 would reach 866 .

\section{Major publishing countries and institutions}

Tableau was used to analyze the number of national publications of heavy metal contaminated soil remediation research articles visually. As shown in Figure 2, the number of articles from China was 2024, which accounted for $35.30 \%$ of the total publications. It was 3.51 times higher than America

Table 1: Document type information of literature reports during 2001-2019.

\begin{tabular}{|l|c|c|}
\hline Type of Article & Amount & Percentage \\
\hline Article & 4897 & $85.418 \%$ \\
\hline Proceedings Paper & 625 & $10.902 \%$ \\
\hline Review & 468 & $8.163 \%$ \\
\hline Early Access & 58 & $1.012 \%$ \\
\hline Book Chapter & 15 & $0.262 \%$ \\
\hline Editorial Material & 8 & $0.140 \%$ \\
\hline Meeting Abstract & 5 & $0.087 \%$ \\
\hline Retracted Publication & 3 & $0.052 \%$ \\
\hline Correction & 2 & $0.035 \%$ \\
\hline Letter & 1 & $0.017 \%$ \\
\hline
\end{tabular}

in the second and 6.04 times higher than Spanish in the third. This result showed that although research on soil heavy metal pollution remediation in China started late, it attached great importance in this field and achieved a series of results.

Furthermore, VOSviewer was used to perform a cluster analysis on the countries that published articles. The results showed that all the countries were divided into 5 categories. China, which showed the highest node size and link strength in the network map, expressed the highest centrality. The next countries with a certain degree of centrality were America, Spanish, South Korea, and Italy Figure 3.

As shown in Table 2, there were 3577 institutions worldwide which conducted research on the remediation technology of heavy metal contaminated soil. Seven of the top ten research institutions with publication volume were in China. Among them, CHINESE ACADEMY OF SCIENCES ranked first with 439 articles published which accounted for $7.66 \%$, UNIVERSITY OF CHINESE ACADEMY OF SCIENCES ranked second with 148 articles published which accounted for 2.58\%; and INSTITUTE OF SOIL SCIENCE, CHINESE ACADEMY OF SCIENCES ranked third with 127 articles published which accounted for $2.21 \%$. In addition, in terms of the $\mathrm{H}$ index and the average number of citations, CHINESE ACADEMY OF SCIENCES and CONSEJO SUPERIOR DE INVESTIGACIONES CIENTIFICAS had the highest research level in soil remediation of heavy metal pollution.

\section{Major journals and authors}

In the field of soil heavy metal pollution remediation, there were14435 authors involved, of which 251 had published more than 10 articles, and 65 had published more than 20 articles. The top ten authors' information was shown in Table 3. Zeng Guangming had the highest $\mathrm{H}$ index and his citation frequency per article was also the first. What's more, Yong Sik $\mathrm{Ok}^{\prime} \mathrm{s} \mathrm{H}$ index and citation frequency per article were also very high. It implicated than the two scholars had a high degree of influence in this field.

There were 968 related research journals. According to the number of publications, the top 10 journals were selected, and the publication volume, $\mathrm{H}$ index, country and impact factor (2018) were listed in Table 4. There are 20 journals with more than 50 articles published, and 10 journals with more than 100 articles. Among them, "CHEMOSPHERE" published 368 articles about the remediation of heavy metal contaminated soil, which accounted for $6.42 \%$. In addition, these articles in this journal had been cited 15561 times, and the impact factor was also in the forefront, making it become the most influential journal in this field.

Figure 4 showed the results of the co-occurrence analysis of various journals by VOSiewer. It indicated that "CHEMOSPHERE" had the highest centrality, which further confirmed its core position in the field of heavy metal contaminated soil remediation.

\section{Citation frequency analysis}

Table 5 listed the top 10 articles according to the total number of citations. Among them, "Biochar as a sorbent for 


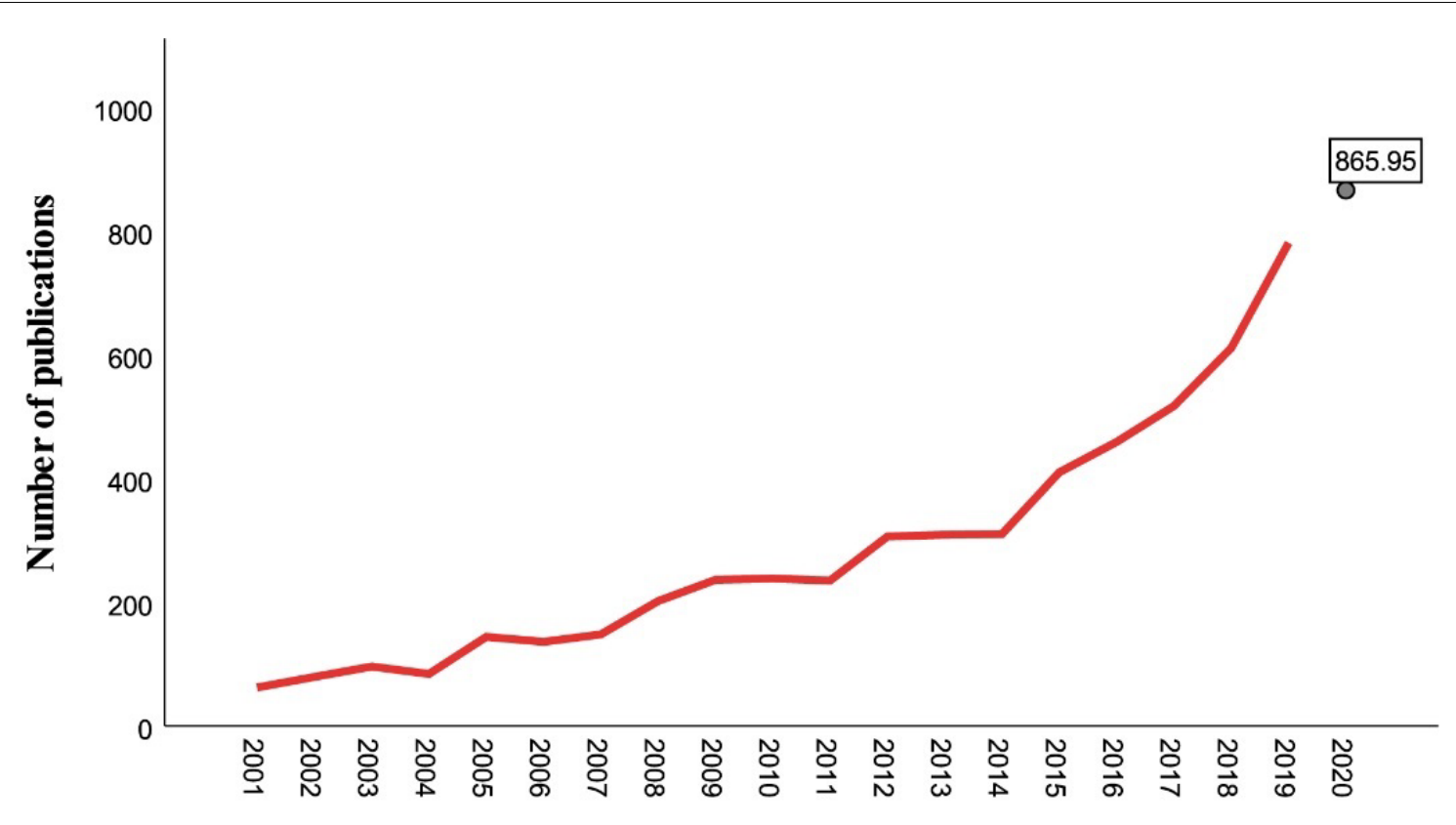

\section{Year}

Figure 1: Quantitative distribution of published related articles in 1983-2019 and the prediction of 2020.
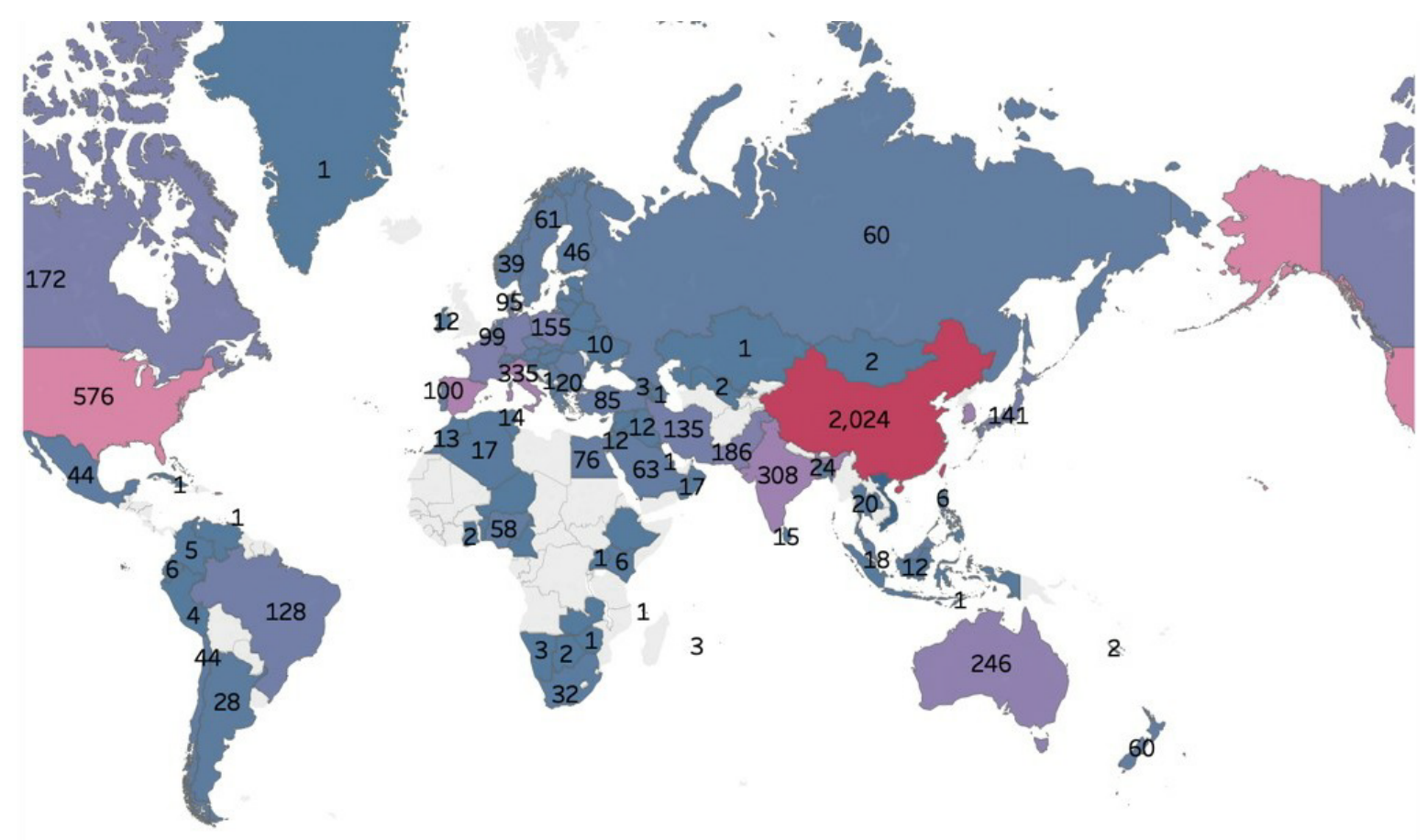

Figure 2: Statistical map of national releases of heavy metal contaminated soil remediation research literature. 
Citation: Guo R, Zheng X, Yang Y, et al. (2021) Remediation of Heavy Metals Contaminated Soils: A bibliometric Network Analysis. J Soil Water Sci 5(2):205-217

Table 2: Top 10 institutions of remediation of heavy metal contamination in soils.

\begin{tabular}{|c|c|c|c|c|c|c|}
\hline NO. & Institution & Amount & Percentage & $H$-index & $\begin{array}{l}\text { Total number of } \\
\text { citations }\end{array}$ & $\begin{array}{c}\text { The average number of } \\
\text { citations }\end{array}$ \\
\hline 1 & CHINESE ACADEMY OF SCIENCES & 439 & 7.66 & 50 & 10348 & 23.57 \\
\hline 2 & $\begin{array}{l}\text { UNIVERSITY OF CHINESE ACADEMY OF SCIENCES } \\
\text { CAS }\end{array}$ & 148 & 2.58 & 29 & 3420 & 23.11 \\
\hline 3 & INSTITUTE OF SOIL SCIENCE CAS & 127 & 2.21 & 28 & 3032 & 23.87 \\
\hline 4 & $\begin{array}{l}\text { CONSEJO SUPERIOR DE INVESTIGACIONES } \\
\text { CIENTIFICAS }\end{array}$ & 121 & 2.11 & 40 & 5250 & 43.39 \\
\hline 5 & ZHEJIANG UNIVERSITY & 90 & 1.57 & 26 & 2484 & 27.6 \\
\hline 6 & $\begin{array}{l}\text { CENTRE NATIONAL DE LA RECHERCHE } \\
\text { SCIENTIFIQUE }\end{array}$ & 76 & 1.32 & 22 & 1979 & 26.04 \\
\hline 7 & CHINESE ACADEMY OF AGRICULTURAL SCIENCES & 76 & 1.32 & 18 & 1225 & 16.12 \\
\hline 8 & TECHNICAL UNIVERSITY OF DENMARK & 71 & 1.24 & 21 & 1314 & 18.51 \\
\hline 9 & CHINA UNIVERSITY OF GEOSCIENCES & 70 & 1.22 & 11 & 625 & 8.93 \\
\hline 10 & CENTRAL SOUTH UNIVERSITY & 68 & 1.19 & 18 & 1000 & 14.71 \\
\hline
\end{tabular}

Table 3: Top 10 authors of remediation of heavy metal contamination in soils.

\begin{tabular}{|l|l|c|c|c|c|}
\hline No. & Name & Amount & H-index & $\begin{array}{c}\text { Total number of } \\
\text { citations }\end{array}$ & $\begin{array}{c}\text { The average number of } \\
\text { citations }\end{array}$ \\
\hline 1 & Yong Sik Ok & 71 & 63 & 2166 & 30.5 \\
\hline $\mathbf{2}$ & Tsang, Chiu-Wa, Daniel & 66 & 14 & 904 & 13.69 \\
\hline 3 & Lisbeth M Ottosen & 64 & 30 & 1172 & 18.32 \\
\hline 4 & Krishna R Reddy & 47 & 60 & 1448 & 30.81 \\
\hline 5 & Guangming Zeng & 44 & 113 & 1742 & 39.58 \\
\hline 6 & Kitae Baek & 38 & 35 & 772 & 20.31 \\
\hline 7 & Pernille E Jensen & 37 & 17 & 506 & 13.68 \\
\hline 8 & Domen Lestan & 30 & 28 & 984 & 32.81 \\
\hline 9 & Yingming Xu & 29 & 29 & 572 & 19.71 \\
\hline 10 & Rongliang Qiu & 28 & 38 & 675 & 24.09 \\
\hline
\end{tabular}

Table 4: Top 10 journals of Remediation of heavy metal contamination in soils.

\begin{tabular}{|c|c|c|c|c|c|c|}
\hline No. & Journal name & Amount & $\underline{H \text {-index }}$ & $\begin{array}{l}\text { The number } \\
\text { of citations }\end{array}$ & Country & IF \\
\hline 1 & CHEMOSPHERE & 368 & 91 & 15561 & Britain & 5.108 \\
\hline 2 & ENVIRONMENTAL SCIENCE AND POLLUTION RESEARCH & 339 & 71 & 4736 & Germany & 2.914 \\
\hline 3 & JOURNAL OF HAZARDOUS MATERIALS & 321 & 100 & 16267 & Netherlands & 7.65 \\
\hline 4 & SCIENCE OF THE TOTAL ENVIRONMENT & 241 & 113 & 6131 & Netherlands & 5.589 \\
\hline 5 & ENVIRONMENTAL POLLUTION & 166 & 88 & 9511 & Britain & 5.714 \\
\hline 6 & JOURNAL OF ENVIRONMENTAL MANAGEMENT & 154 & 78 & 3757 & Britain & 4.865 \\
\hline 7 & WATER AIR AND SOIL POLLUTION & 152 & 100 & 3375 & Netherlands & 1.774 \\
\hline 8 & JOURNAL OF SOILS AND SEDIMENTS & 141 & 39 & 1935 & Germany & 2.669 \\
\hline 9 & ECOTOXICOLOGY AND ENVIRONMENTAL SAFETY & 136 & 110 & 2013 & Britain & 4.527 \\
\hline 10 & INTERNATIONAL JOURNAL OF PHYTOREMEDIATION & 134 & 49 & 1905 & U.S.A & 2.237 \\
\hline
\end{tabular}

contaminant management in soil and water : A review" in "CHEMOSPHERE" at 2014, of which the author was Ok, Yong Sik from Korea University [8], had been cited 1363 times, which ranked first. This article reviewed the research and application history of biochar in environmental remediation, and proposed that the physical structure and composition of biochar were essential for the adsorption of heavy metals in soil and water. The adsorption capacity depended on the specific surface area, microporosity and the hydrophobicity of the biochar material. At the same time, it pointed out that the future research direction should focus on the longterm stability and influence of biochar after the adsorption of pollutants in the soil. In addition, "Phytoremediation of heavy metals-Concepts and applications" [4] had also been cited more than 1000 times. The article believed that the physical and chemical methods for cleaning and remediating heavy metals contaminated soil had serious limitations while phytoremediation was a better way. Phytoremediation was an environmentally friendly, new technology driven by solar energy, currently in the research stage. The research on phytoremediation was interdisciplinary in nature and required background knowledge in soil science, botany, ecology, soil microbiology, and environmental science. And the interaction between heavy metals, soil, microorganisms and plant roots should be studied more deeply. At the same time, advances in spectroscopy and chromatographic techniques were used to 
Citation: Guo R, Zheng X, Yang Y, et al. (2021) Remediation of Heavy Metals Contaminated Soils: A bibliometric Network Analysis. J Soil Water Sci 5(2):205-217

Table 5: Top 10 cited references and citations.

\begin{tabular}{|c|c|c|c|c|c|}
\hline No. & Title & Author & Journal name & Time & $\begin{array}{l}\text { Citation } \\
\text { Count }\end{array}$ \\
\hline 1 & $\begin{array}{l}\text { Biochar as a sorbent for contaminant management in soil and } \\
\text { water: A review }\end{array}$ & Ok, Yong Sik & CHEMOSPHERE & 2014 & 1363 \\
\hline 2 & Phytoremediation of heavy metals-Concepts and applications & $\begin{array}{l}\text { Sajad, } \\
\text { Muhammad } \\
\text { Anwar }\end{array}$ & CHEMOSPHERE & 2013 & 1091 \\
\hline 3 & $\begin{array}{l}\text { Organic and inorganic contaminants removal from water with } \\
\text { biochar, a renewable, low cost and sustainable adsorbent - A } \\
\text { critical review }\end{array}$ & $\begin{array}{l}\text { Pittman, } \\
\text { Charles U.Jr. }\end{array}$ & BIORESOURCE TECHNOLOGY & 2014 & 854 \\
\hline 4 & $\begin{array}{l}\text { Remediation technologies for metal-contaminated soils and } \\
\text { groundwater: an evaluation }\end{array}$ & Gibbs, BF & ENGINEERING GEOLOGY & 2001 & 840 \\
\hline 5 & Environmental applications for biosurfactants & Mulligan, $\mathrm{CN}$ & ENVIRONMENTAL POLLUTION & 2005 & 807 \\
\hline 6 & $\begin{array}{l}\text { A review of biochars' potential role in the remediation, } \\
\text { revegetation, and restoration of contaminated soils }\end{array}$ & Sizmur, Tom & ENVIRONMENTAL POLLUTION & 2011 & 731 \\
\hline 7 & Phytoextraction of toxic metals: A review of biological mechanisms & Lasat, MM & $\begin{array}{l}\text { JOURNAL OF ENVIRONMENTAL } \\
\text { QUALITY }\end{array}$ & 2002 & 684 \\
\hline 8 & $\begin{array}{l}\text { Remediation of heavy metal(loid)s contaminated soils - To mobilize } \\
\text { or to immobilize? }\end{array}$ & $\begin{array}{l}\text { Scheckel, } \\
\text { Kirk }\end{array}$ & $\begin{array}{l}\text { JOURNAL OF HAZARDOUS } \\
\text { MATERIALS }\end{array}$ & 2014 & 671 \\
\hline 9 & Trace elements in agroecosystems and impacts on the environment & Stoffella, PJ & $\begin{array}{l}\text { JOURNAL OF TRACE ELEMENTS } \\
\text { IN MEDICINE AND BIOLOGY }\end{array}$ & 2005 & 645 \\
\hline 10 & $\begin{array}{l}\text { Nanoscale zero-valent iron: Future prospects for an emerging water } \\
\text { treatment technology }\end{array}$ & Scott, T. B. & $\begin{array}{l}\text { JOURNAL OF HAZARDOUS } \\
\text { MATERIALS }\end{array}$ & 2012 & 589 \\
\hline
\end{tabular}

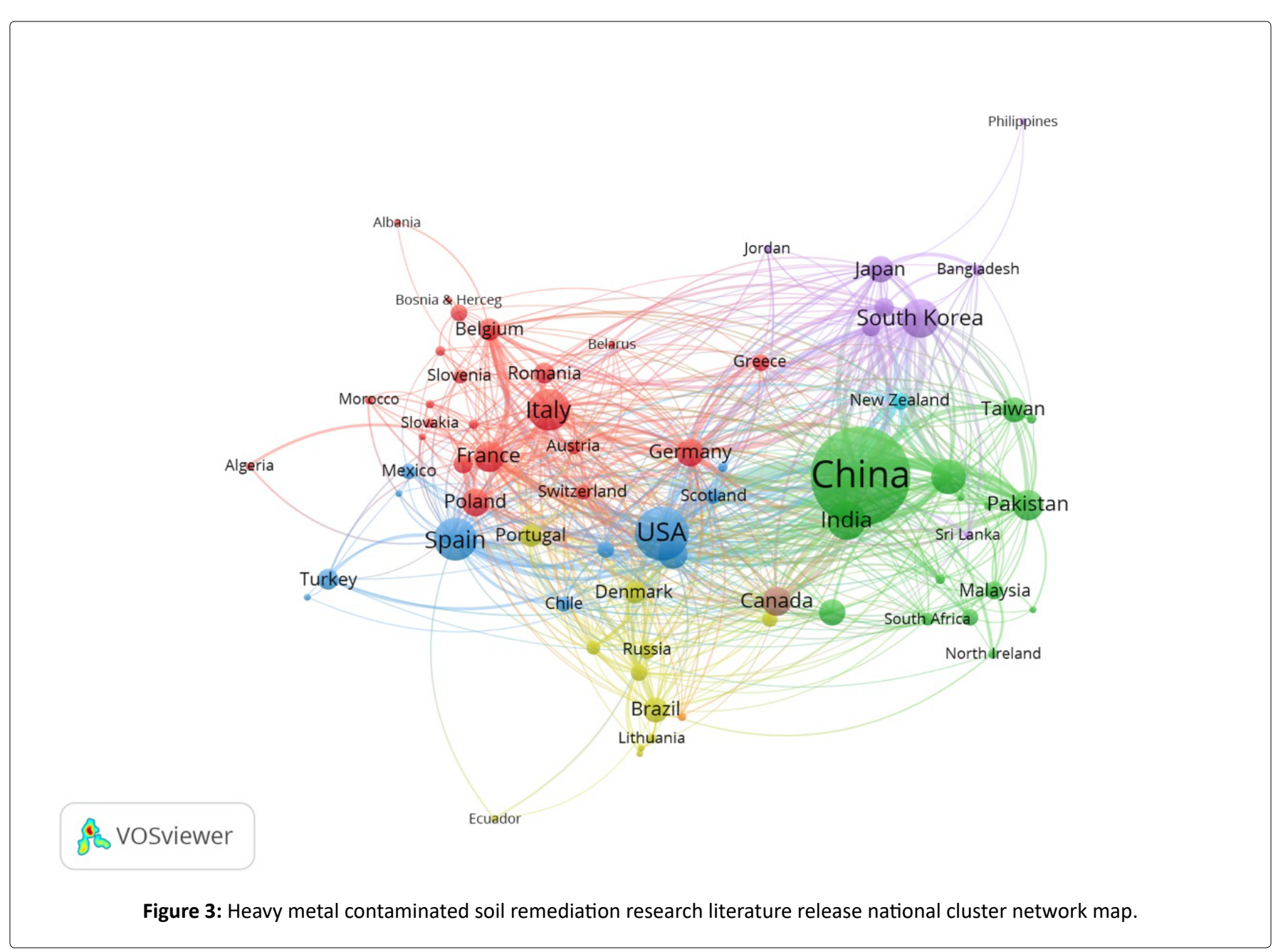


Citation: Guo R, Zheng X, Yang Y, et al. (2021) Remediation of Heavy Metals Contaminated Soils: A bibliometric Network Analysis. J Soil Water Sci 5(2):205-217

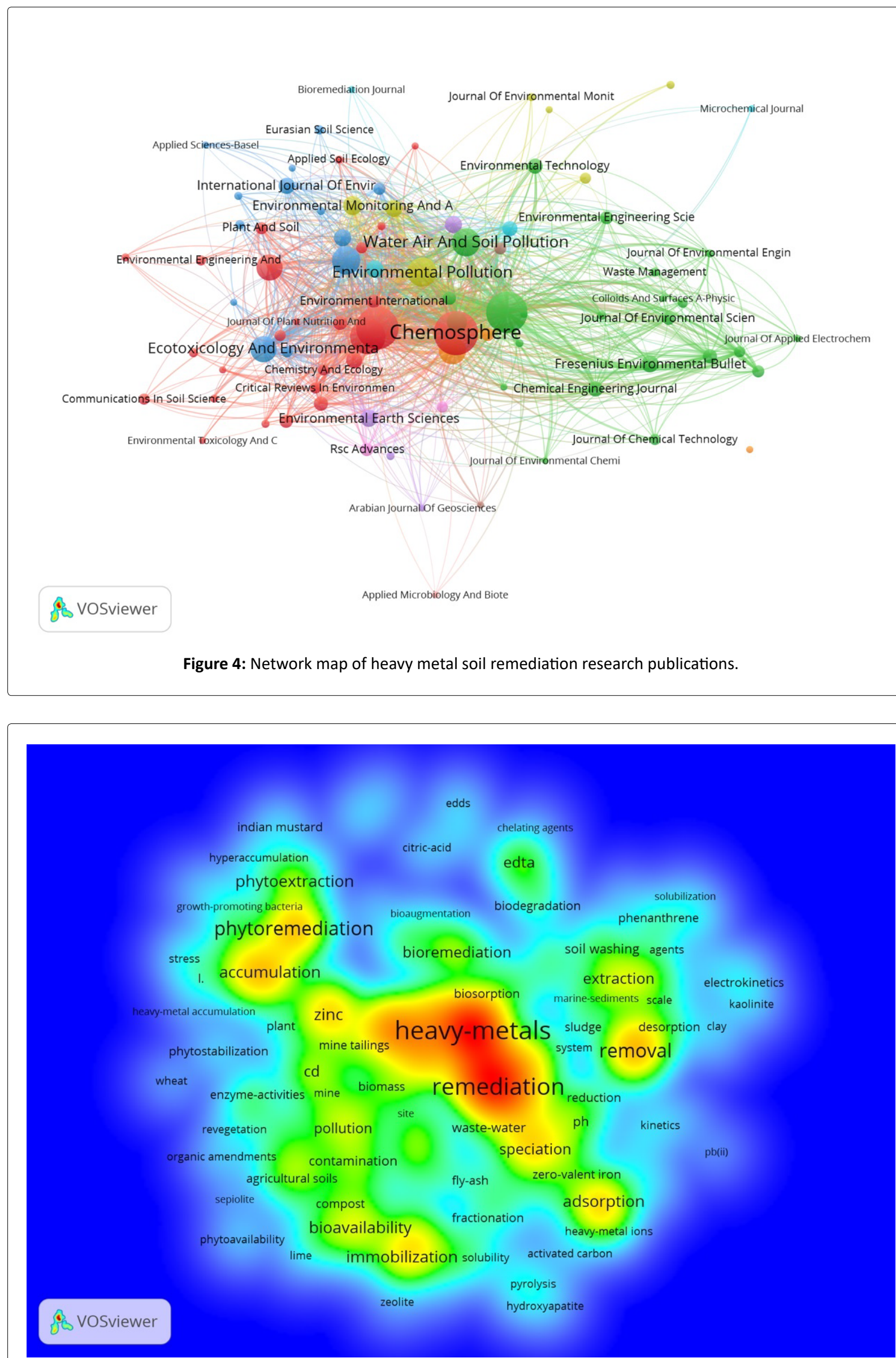

Figure 5: Keywords co-occurrence frequency density map. 
improve the research on the migration and transformation of metal ions in plant tissues. Furthermore, it would also enhance the understanding of the hyperaccumulation and tolerance of related plants. The remaining articles were basically cited more than 600 times. Such a high citation frequency showed that the attention to heavy metals in the soil had become a hot spot in the field of environmental remediation.

\section{Keyword analysis}

\section{Keyword co-occurrence frequency analysis}

VOSviewer software was used to visually analyze the 14,991 keywords that appeared in the retrieved 5,733 documents, and 14 of them appeared frequently more than 500 times. As shown in Figure 5, common keywords include heavy metals, remediation, cadmium, cause, migration, phytoremediation, soil, accumulation, zinc, contaminated soil, copper, immobilization, lead, adsorption, etc. This can be used to analyze heavy metal contaminated soil Provide a reference for the research direction of restoration.

\section{Keyword co-occurrence cluster analysis}

Use VOSviewer software to analyze the keyword clusters with a frequency of more than 35 , and the results are shown in Figure 6. The 249 keywords are divided into 3 clusters. The main focus of cluster 1 is phytoremediation, growthpromoting bacteria, accumulation, plants, plant stabilization, plant extraction, bioremediation, and Indian mustard. Scholars in this part mainly use phytoremediation methods to repair heavy metal contaminated soil and explore the green repair technology of phytoremediation, such as studying the growth factors that affect hyperaccumulation plants [9] and using growth-promoting bacteria to promote the growth of repair plants [10]. Common keywords for cluster 2 are EDTA, extraction, electrokinetics, migration, sediment, EDDS, etc. This part focuses on some physical and chemical repair methods, especially the use of chemical additives such as EDTA and EDDS to help adsorption Heavy metals [11]; in addition, it starts with the microscopic mechanism of electrokinetics to summarize the migration and transformation laws of heavy metals. Cluster 3 focuses on immobilization, stabilization, plant availability, hydroxyapatite, zeolite, activated carbon, lime, zero-valent iron, agricultural soil, etc. This part focuses on the use of immobilization and stabilization as a repair technician. Use different types of repair materials to adsorb and fix heavy metals in the soil.

\section{Keyword co-occurrence hotspot evolution analysis}

By analyzing the appearance time of hot keywords, the evolution path of the research hotspots of heavy metal contaminated soil can be obtained. Through the VOSviewer software, after analyzing the occurrence time of the keywords in Figure 7, we can get a line from zinc, EDTA, extraction, kaolin to phytoremediation, accumulation, bioremediation to immobilization, organic amendments, zero-valent iron, agriculture The hotspot evolution path of heavy metal contaminated soil remediation research.

\section{Keyword emergence analysis}

The analysis of emergent keywords can well reflect the research hotspots and frontiers of heavy metal contaminated soil remediation. The emergence strength of a certain keyword represents the popularity of the keyword. In this study, CiteSpace software was used for visual analysis. Based on the co-occurrence analysis of heavy metal contaminated soil remediation keywords, the number of keywords was set to 20 , and a distribution map of heavy metal contaminated soil remediation emergent keywords sorted by emergence intensity was generated. It can be seen from Figure 8 that the five keywords with the highest emergence strength are: "Zinc", emergence strength 15.0031; "electrokinetics", emergence strength 13.3787; "kaolinite", emergence strength 11.1339; "electroosmotic flow", the emergent strength of 10.4674; "clay", the emergent strength of 9.7156. It can be seen that zinc is a research hotspot for the types of heavy metals; for repair technology, electric repair and the use of mineral material immobilization are the main research directions in this period.

\section{Research hotspots and development trends based on keyword analysis}

Through co-occurrence analysis of keywords in 5,733 documents, and combining with highly cited documents, the current research hotspots of heavy metal contaminated soil remediation are classified into the following two aspects according to their attributes.

\section{Types and Forms of Heavy Metals in Soil Pollution}

Heavy metals in the soil have different existing forms, which can be generally divided into exchangeable state, carbonate-bound state, iron (manganese) oxide-bound state, organic-bound state, and residue state. In these main forms, most of the heavy metals exist in the form of precipitation. According to related studies, the toxicity of heavy metals in the soil does not depend on their total content, but on the concentration of highly reactive parts (such as exchangeable heavy metals) in the soil [12]. The concentration of heavy metals in this part determines its toxicity to the outside world.

On the other hand, metals such as zinc, nickel, manganese, iron, copper, and molybdenum are also essential elements for plant growth and development and play an important role in some physiological processes, such as the electron transfer system in photosynthesis and the respiration of plants [13], it is also an activator of many conjugated enzymes [14]. However, with the discharge of industrial activities, after excessive heavy metals are accumulated in the soil and enriched in plants, the heavy metals will induce oxidative stress along with the metabolism of organisms, causing the organisms to produce high concentrations of reactive oxygen species [15], such as Superoxide radicals, hydroxyl radicals, and hydrogen peroxide. These reactive oxygen species can destroy biological molecules such as lipids, proteins, and nucleic acids, and cause harm to the organism. 

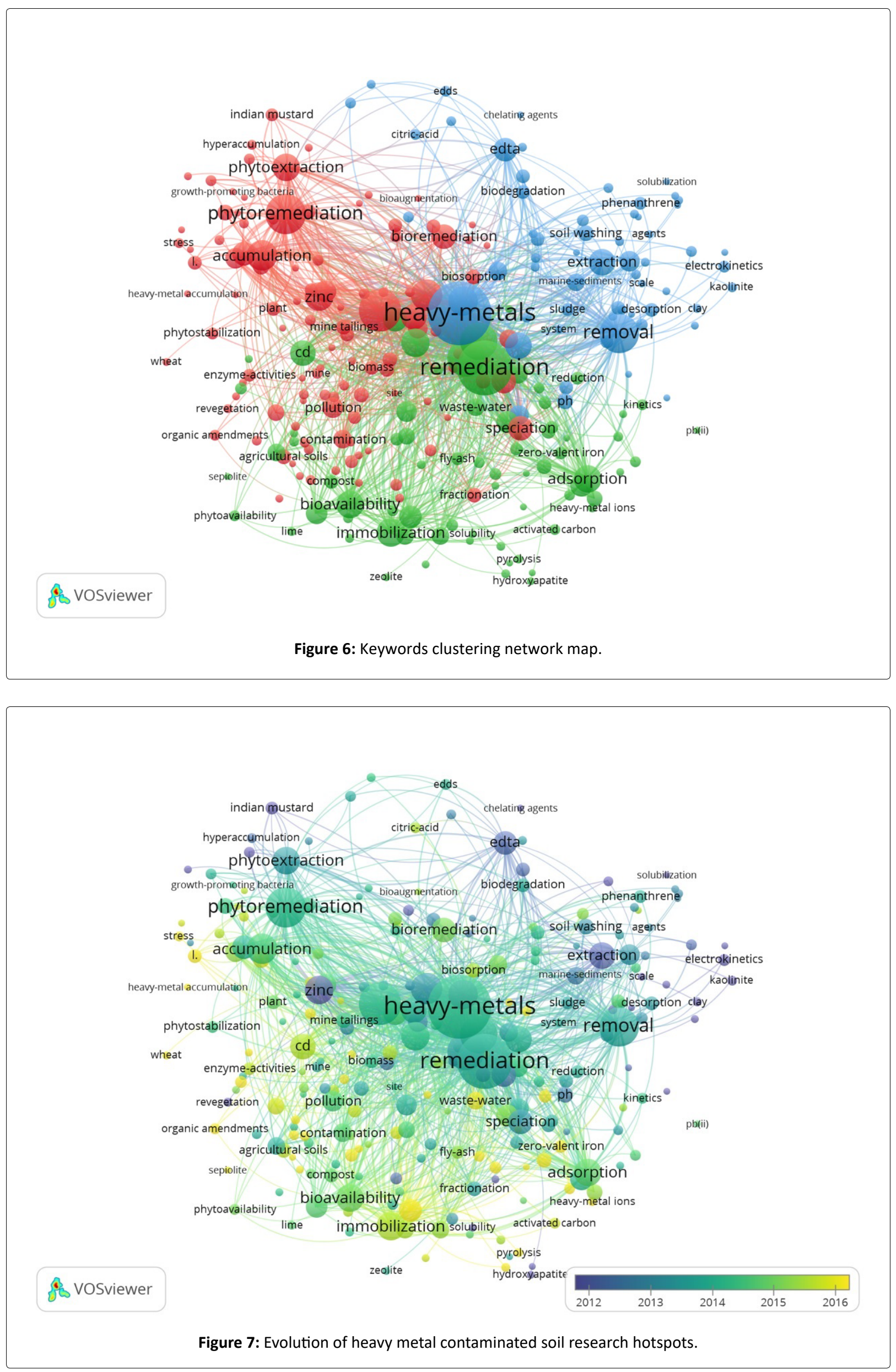


\section{Top 20 Keywords with the Strongest Citation Bursts}

\begin{tabular}{|c|c|c|c|c|}
\hline Keywords & Year & Strength Begin & End & $2001-2019$ \\
\hline zinc & 2001 & 15.00312001 & 2008 & \\
\hline electrokinetics & 2001 & 13.37872001 & 2011 & \\
\hline kaolinite & 2001 & 11.13392001 & 2005 & \\
\hline electroosmosis & 2001 & 10.46742001 & 2010 & \\
\hline clay & 2001 & 9.71562001 & 2010 & \\
\hline chromium & 2001 & 8.7152002 & 2007 & \\
\hline soil pollution & 2001 & 8.63832002 & 2004 & \\
\hline revegetation & 2001 & 7.92732002 & 2010 & \\
\hline chemistry & 2001 & 6.80122001 & 2005 & \\
\hline metal & 2001 & 5.93472001 & 2003 & \\
\hline apatite & 2001 & 5.81852001 & 2007 & \\
\hline hydroxyapatite & 2001 & 5.65982001 & 2008 & \\
\hline edta extraction & 2001 & 5.00382001 & 2010 & \\
\hline polluted soil & 2001 & 4.33132001 & 2005 & \\
\hline speciation & 2001 & 4.08912001 & 2002 & \\
\hline column & 2001 & 3.97452001 & 2006 & \\
\hline population & 2001 & 3.80912002 & 2008 & \\
\hline lead immobilization & 2001 & 3.77172001 & 2008 & \\
\hline iron oxide & 2001 & 3.49122001 & 2008 & \\
\hline arsenic & 2001 & 3.17772002 & 2009 & \\
\hline
\end{tabular}

Figure 8: Highlight map of hot keywords.

For agricultural land, heavy metal pollution will have a huge impact on food security. It is estimated that about $20 \%$ of the total cultivated land in China is polluted to varying degrees [16]. In most developed countries, agricultural land is rarely polluted. For example, about $93 \%$ of agricultural land in Europe can be safely used for food production [17]. However, the monitoring of my country's soil environmental safety is still immature, and the comprehensive control of soil heavy metal pollution cannot be achieved. Therefore, actively carrying out the risk assessment of heavy metal pollutants in the soil, conducting national soil surveys to understand the soil conditions in my country, and formulating different soil environmental quality standards applicable to various regions is vital to the formulation of relevant land use plans. In the survey and evaluation, including species formation and bioavailability into the measurement and evaluation criteria should also be the focus of future soil heavy metal management.

\section{Remediation technology of heavy metal contaminated soil}

The remediation technology of metal contaminated soil mainly includes electric remediation, phytoremediation, immobilization technology, etc.

Electric repair technology: Electrokinetic remediation is the use of electric potential gradients to remove heavy metals from the soil through electromigration and electroosmosis [18]. As early as the 1930s, for the high-salinity soil of a certain place in India, some scholars used the method of electric remediation to conduct experiments on the sodium salt in the alkaline soil to study the restoration of the alkaline soil to the level of arable land [19]. Laboratory and field results show that by applying a DC electric field, sodium ions can be extracted from the soil. Compared with traditional methods, the unique advantage of electric remediation technology is that it can achieve very good results in low-permeability soils where other remediation methods cannot achieve good results. At the same time, electric repair technology is not affected by the geological location and can be carried out on sites where civil excavation is not possible. Finally, electric remediation can simultaneously act on organic and inorganic pollutants in the soil.

Higher cost has become the main bottleneck for the widespread application of electric repair. The total cost of electric repair mainly includes the manufacture and installation of electrodes, power consumption, labor, and other fixed costs, etc. [20]. Among them, power consumption is the main factor in the total cost of electric repair. Factors including soil characteristics, pollution conditions, electrode configuration, or spacing also significantly affect the energy consumption in the electric remediation process. In addition, while removing heavy metal elements, electric remediation 
may consume a large number of macroelements in the soil [21] (potassium, sodium, calcium, magnesium, iron, and manganese), most of which are elements necessary for plant growth. The decrease in soil pH during the restoration process is beneficial to the release of heavy metals in the soil, but it will destroy the soil composition [22].

In view of the shortcomings of electric repair, further, improve the electric repair technology, future work should focus on: First, in-depth study of the interaction mechanism between heavy metals and soil in the electric repair process. For example, it is currently considered that it is difficult to enrich heavy metals such as cadmium and lead in the soil, but many experiments have shown that cadmium and lead in the soil can be moved and concentrated in local areas [23]. As well as the mechanism when the current flows through the soil, there is no good theoretical explanation for some electrical phenomena observed during the restoration process. The second is to address the consumption of conventional metal elements in the electric repair process. For example, the development of pulsed electric treatment to reduce the consumption of conventional metal elements and electric energy [24]. The third is to conduct in-depth research on electrode materials, ion resin isolation walls, and other materials. Fourth, electric remediation technology integrates chemical engineering and technology, environmental science and engineering, civil engineering, materials science and engineering, and soil science. The terms and symbols need to be further unified to promote the integration of disciplines.

Phytoremediation technology: Phytoremediation refers to planting plants in contaminated soil and relying on solar energy to remove heavy metals in the soil or stabilize it in a harmless state [25]. The essence is to use the microorganisms in plants and soil to reduce the concentration or toxic effects of pollutants in the environment. The advantages of phytoremediation are simple operation, no professional or expensive equipment; beautification of the environment. Phytoremediation involves multiple processes, including heavy metal absorption (plant extraction), heavy metal accumulation and transport (plant accumulation), release to the atmosphere (plant volatilization), and root zone stabilization (plant stabilization).

But phytoremediation also has certain limitations. The phytoremediation process is generally slow, and the actual repair rate depends on the growth cycle of the selected hyperaccumulating plants, and in the actual remediation process, multiple plant growth cycles are required to achieve the restoration goal. This makes the phytoremediation time generally need to last several months or years. Most hyperaccumulative plants such as nightshade [4], centipede [26], Indian mustard, etc. have low repair efficiency mainly due to the slow growth rate and small biomass. At the same time, phytoremediation technology is difficult to remove heavy metals with low mobility in the soil, which means that the bioavailability of pollutants in the soil is limited. Finally, phytoremediation technology first needs the soil to be repaired to meet the basic needs of plant growth, so nonbioremediation methods can only be selected for heavily polluted sites. At the same time, the relevant physiological preparations of hyperaccumulating plants are still unclear, and their physiological functions have not been fully explored. In addition, transgenic plants, chelate-assisted phytoremediation, and microbial-assisted phytoremediation have gradually become research hotspots in the direction of phytoremediation.

Phytoremediation is a relatively new technology for remediation of heavy metal contaminated soil. The main technical advantages are cost-effectiveness and environmental protection. For its shortcomings, in-depth research should be done on the following three points in the future: One is to further strengthen hyperaccumulative plants through genetic engineering. Through conventional plant breeding techniques or genetic hybridization methods, certain traits conducive to heavy metal hyperaccumulation are transformed into more suitable plants to cultivate hyperaccumulation engineering plants. Second, in view of the low mobility and bioavailability of some heavy metals, some synthetic chelating agents are used to assist plants in the absorption of pollutants. At the same time, attention is paid to the negative effects of added chelating agents on the soil [27]. The third is to pay attention to the treatment technology of plant residues after the enrichment of pollutants. Recovering heavy metals from plant biomass or safely disposing of harvested plants is still currently restricted. More research should be done technically to properly dispose of recycled biomass or recover heavy metals extracted from soil.

Immobilization technology: The immobilization technology is to add exogenous reagents to the soil to convert soluble and exchangeable heavy metals into a form with low mobility and dissolution rate, so as to minimize its potential toxicity to plants and microorganisms. Stabilization technology is to mix exogenous materials with contaminated soil to induce physical and chemical interactions between heavy metals and materials to reduce the mobility of heavy metals. Commonly used materials are carbonates, phosphates, clay minerals, biochar, compost, and chitosan. These soil remediation reagents reduce the bioavailability and leaching potential of heavy metals by inducing physical and chemical processes including precipitation, complexation, adsorption, and ion exchange. Among them, clay minerals [28] and biochar [29] are the most abundant.

Clay minerals are natural mineral materials with low prices and abundant reserves that are widely present in the world and have been effectively used for the remediation of many pollutants. In general, the adsorption performance of the material depends on the following four aspects: Clay properties, repair time, clay dosage, and soil pH. Clay minerals are very suitable to act as adsorbents for heavy metals due to their high cation exchange capacity and large specific surface area. The most common ones are bentonite [30], montmorillonite [31], attapulgite [32], etc. These clay minerals all have a high specific surface area, cation exchange capacity, and chemical stability. In addition, the adsorption capacity of clay minerals can be further improved by modification; at the same time, the cation exchange capacity and specific surface area of the modification can be increased, and its repair potential can be enhanced. Common modification methods 
include thermal modification, acid modification, organic material loading, and nano-zero-valent iron. Among them, nano-zero-valent iron has become a kind of modification that has attracted much attention in recent years due to its strong reactivity (strong reduction), high specific surface area, and multiple active sites on the surface that can contact with heavy metal cations Material [33].

Although the modification of mineral materials can effectively improve the repairing effect of heavy metals, the modification will increase the cost, and there is a risk that the chemical reagents used in the modification will be released into the soil and cause pollution. For example, the use of quaternary ammonium cationic surfactants to modify clay minerals, while improving the repair effect, may cause quaternary ammonium salts to accumulate in the soil and cause toxicity [34]; on the one hand, nano-zero-valent iron is easily oxidized and loses activity, On the other hand, nanomaterials with extremely small diameters can easily enter the cells of organisms. At present, the understanding of the possible effects of nanomaterials in the environment is still very limited [35,36].

For clay minerals, the future research directions are as follows: First, continue to find suitable modification methods, as far as possible, do not use chemical modification methods or enhance the bonding strength to reduce the risk of chemical agents being released into the soil environment. At the same time, the adsorption rate of clay minerals and the stability after adsorption of pollutants are further improved. The second is to formulate relevant standards to standardize indicators such as the number of clay minerals used in the actual restoration process to avoid other adverse effects on the soil caused by excessive use.

In addition to clay minerals, biochar has also shown good effects in fixing heavy metals in the soil and has also been used in actual site restoration. The International Biochar Action Organization defines it as: "Biochar is a solid material obtained through the thermochemical conversion of biomass in an oxygen-deficient environment" [37]. In the soil, the mechanism of action of biochar with heavy metals includes electrostatic adsorption, ion exchange, complexation, and precipitation. Biochar affects the mobility and biological availability of heavy metals by affecting the physical and chemical properties of the soil itself, such as $\mathrm{pH}$, mineral composition, and cation exchange capacity. Biochar itself has many functional groups, and all have high reactivity, especially $\mathrm{Cr}(\mathrm{VI})$ can be reduced to $\mathrm{Cr}$ (III) with lower toxicity [38]. Since the solubility of $\mathrm{Cr}$ (III) is lower than that of $\mathrm{Cr}$ $(\mathrm{VI})$, this reduction effect can also immobilize chromium ions, reducing the mobility and achieving the purpose of repair.

However, the density of biochar is low, and dust may be generated during the actual restoration process. The amount of dust emissions increases with the increase in the application amount, which is likely to cause secondary pollution and threaten the health of personnel. In addition, when heavy metals are adsorbed and enriched in biochar, it may increase the heavy metal content in the growing crops or reduce the germination rate and root length of the crops [39].
Faced with these problems, future research can focus on: First, in-depth study of the long-term effects of biochar on heavy metal contaminated soil; second, proposed targeted solutions for the possible adverse effects of biochar on the soil environment; third, Further explore the direct or indirect mechanism of biochar on heavy metals in the soil to provide theoretical support for the efficient restoration.

\section{Conclusion}

1. From the changing trend of the number of articles published on the remediation of heavy metal contaminated soil, it can be seen that with the continuous attention to environmental pollution control worldwide, the number of articles in the field of remediation of heavy metal contaminated soil continues to increase, and the growth trend in recent years has been obvious. Based on time series analysis, it is predicted that future research on the remediation of heavy metal contaminated soil will continue to grow.

2. As far as the countries and institutions are concerned, the importance of my country's importance to heavy metal contaminated soil is the most important in the world. The number of publications from China accounts for $35 \%$ of 5,733 articles published in more than 100 countries in the world. Seven colleges and institutions from China ranked in the top 10 , with 1,018 posts accounting for $17.8 \%$ of the world's total posts.

3. The publications of heavy metal contaminated soil are concentrated in several publications with high environmental impact factors. Among them, "CHEMOSPHERE" articles on the remediation of heavy metal contaminated soil have been cited up to 15,561 times, and the impact factor is also at the forefront. It can be seen the influence and importance of the journal in the field of heavy metal contaminated soil remediation.

4. Keyword cluster analysis focuses on 3 categories. The main focus of cluster 1 is to use phytoremediation methods to remediate heavy metal contaminated soil and to explore phytoremediation, a remediation technology driven by solar energy. Cluster 2 mainly focuses on some physical and chemical repair methods, especially the use of some chelating agents to chelate heavy metal ions to reduce their mobility to achieve the purpose of repair. Cluster 3 focuses on the use of immobilization and stabilization as a repair technology, using different types of repair materials to adsorb and fix heavy metals in the soil.

5. From the perspective of co-occurrence analysis and emergence intensity of keywords, the research hotspots of heavy metal contaminated soil remediation focus on the application of in-situ remediation such as phytoremediation, electric remediation, and immobilization/ stabilization. Comparing different remediation technologies, phytoremediation methods are an effective alternative to physical and chemical methods, which can purify toxic metals from the environment and have better economic and environmental benefits. Combining different repair techniques can complement each other's weaknesses during the repair process to improve repair effects. 


\section{References}

1. Amari T, Ghnaya T, Abdelly C (2017) Nickel, cadmium and lead phytotoxicity and potential of halophytic plants in heavy metal extraction. South African Journal of Botany 111: 99-110.

2. Afonne OJ, Ifediba EC (2020) Heavy Metals risks in plant foodsneed to step up precautionary measures. Curr Opin Toxicol 22: $1-6$.

3. Hazrati S, Farahbakhsh M, Heydarpoor G, et al. (2020) Mitigation in availability and toxicity of multi-metal contaminated soil by combining soil washing and organic amendments stabilization. Ecotoxicol Environ Saf 201:110807.

4. Ali H, Khan E, Sajad MA (2013) Phytoremediation of heavy metals-concepts and applications. Chemosphere 91: 869-881.

5. Yin K, Wang Q, Lv M, et al. (2019) Microorganism remediation strategies towards heavy metals. Chem Eng J 360: 1553-1563.

6. Wang J, Shi L, Zhai L, et al. (2021) Analysis of the long-term effectiveness of biochar immobilization remediation on heavy metal contaminated soil and the potential environmental factors weakening the remediation effect: A review. Ecotoxicol Environ Saf 207: 111261.

7. Zhang $H$, Yuan $X$, Xiong T, et al. (2020) Bioremediation of cocontaminated soil with heavy metals and pesticides: Influence factors, mechanisms and evaluation methods. Chem Eng J 398: 125657.

8. Ahmad M, Rajapaksha AU, Lim JE, et al. (2014) Biochar as a sorbent for contaminant management in soil and water: A review. Chemosphere 99: 19-33.

9. Rostami S, Azhdarpoor A (2019) The application of plant growth regulators to improve phytoremediation of contaminated soils: A review. Chemosphere 220: 818-827.

10. Ahemad M, Kibret M (2014) Mechanisms and applications of plant growth promoting rhizobacteria: Current perspective. Journal of King Saud University-Science 26: 1-20.

11. Ding Z, Wang Q, Hu X (2013) Extraction of heavy metals from water-stable soil aggregates using EDTA. Procedia Environmental Sciences 18: 679-685.

12. Zhang G, Bai J, Zhao Q, et al. (2016) Heavy metals in wetland soils along a wetland-forming chronosequence in the yellow river delta of China: Levels, sources and toxic risks. Ecol Indic 69: 331-339.

13. Hołtra A, Zamorska-Wojdyła D (2020) The pollution indices of trace elements in soils and plants close to the copper and zinc smelting works in Poland's lower Silesia. Environ Sci Pollut Res Int 27: 16086-16099.

14. Robb DA, Pierpoint WS (1983) Metals and micronutrients: Uptake and utilization by plants. Academic press 501-704.

15. Pang X, Wang DH, Xing XY, et al. (2002) Effect of La3+ on the activities of antioxidant enzymes in wheat seedlings under lead stress in solution culture. Chemosphere 47: 1033-1039.

16. Liu S, Wang X, Guo G, et al. (2021) Status and environmental management of soil mercury pollution in China: A review. J Environ Manage 277: 111442.

17. Tóth G, Hermann T, Da Silva, et al. (2016) Heavy metals in agricultural soils of the european union with implications for food safety. Environ Int 88: 299-309.
18. Xu J, Ma Q, Chen C, et al. (2020) Cadmium adsorption behavior of porous and reduced graphene oxide and its potential for promoting cadmium migration during soil electrokinetic remediation. Chemosphere 259: 127441.

19. Lukman S, Bukhari A, Al-Malack MH, et al. (2014) Geochemical modeling of trivalent chromium migration in saline-sodic soil during lasagna process: Impact on soil physicochemical properties. Scientific World Journal 2014:272794.

20. Virkutyte J, Sillanpää M, Latostenmaa P (2002) Electrokinetic soil remediation-critical overview. Sci Total Environ 289: 97-121.

21. Suèr $P$, Gitye $K$, Allard $B$ (2003) Speciation and transport of heavy metals and macroelements during electroremediation. Environ Sci Technol 37: 177-181.

22. Wen D, Fu R, Li Q (2021) Removal of inorganic contaminants in soil by electrokinetic remediation technologies: A review. J Hazard Mater 401: 123345.

23. Gu Y, Yeung A T, Li H (2018) Enhanced electrokinetic remediation of cadmium-contaminated natural clay using organophosphonates in comparison with EDTA. Chin J Chem Eng 26: 1152-1159.

24. Yuan L, Xu X, Li H, et al. (2017) The influence of macroelements on energy consumption during periodic power electrokinetic remediation of heavy metals contaminated black soil. Electrochimica Acta 235: 604-612.

25. Dou X, Dai H, Skuza L, et al. (2020) Strong accumulation capacity of hyperaccumulator solanum nigrum $\mathrm{L}$. for low or insoluble cd compounds in soil and its implication for phytoremediation. Chemosphere 260: 127564.

26. Han R, Dai H, Twardowska I, et al. (2020) Aqueous extracts from the selected hyperaccumulators used as soil additives significantly improve accumulation capacity of solanum nigrum L. for Cd and Pb. J Hazard Mater 394: 122553.

27. Li Z, Wu L, Luo Y, et al. (2018) Changes in metal mobility assessed by EDTA kinetic extraction in three polluted soils after repeated phytoremediation using a cadmium/zinc hyperaccumulator. Chemosphere 194: 432-440.

28. Yi X, Xuefeng L, Yingming X, et al. (2017) Remediation of heavy metal-polluted agricultural soils using clay minerals: A review. Pedosphere 27: 193-204.

29. Liu P, Ptacek CJ, Blowes DW, et al. (2017) Stabilization of mercury in sediment by using biochars under reducing conditions. J Hazard Mater 325: 120-128.

30. Tohdee K, Kaewsichan L, Asadullah (2018) Enhancement of adsorption efficiency of heavy metal $\mathrm{Cu}(\mathrm{II})$ and $\mathrm{Zn}(\mathrm{II})$ onto cationic surfactant modified bentonite. Journal of Environmental Chemical Engineering 6: 2821-2828.

31. Gong B, Wu P, Huang Z, et al. (2016) Efficient inhibition of heavy metal release from mine tailings against acid rain exposure by triethylenetetramine intercalated montmorillonite (TETA-Mt). J Hazard Mater 318: 396-406.

32. Álvarez-Ayuso E, García-Sánchez A (2003) Palygorskite as a feasible amendment to stabilize heavy metal polluted soils. Environ Pollut 125: 337-344.

33. Jiang D, Zeng G, Huang D, et al. (2018) Remediation of contaminated soils by enhanced nanoscale zero valent iron. Environ Res 163: 217-227. 
34. Yang J, Yu K, Liu C (2017) Chromium immobilization in soil using quaternary ammonium cations modified montmorillonite: Characterization and mechanism. J Hazard Mater 321: 73-80.

35. Wallace Hayes A, Sahu SC (2020) Genotoxicity of engineered nanomaterials found in the human environment. Curr Opin Toxicol 19: 68-71.

36. Tilston EL, Collins CD, Mitchell GR, et al. (2013) Nanoscale zerovalent iron alters soil bacterial community structure and inhibits chloroaromatic biodegradation potential in Aroclor 1242-contaminated soil. Environ Pollut 173: 38-46.
37. Onwuka MI, Ozurumba UV, Nkwocha OS (2016) Changes in soil $\mathrm{pH}$ and exchangeable acidity of selected parent materials as influenced by amendments in South East of Nigeria. Journal of Geoscience and Environment Protection 4: 80-88.

38. Dong X, Ma LQ, Li Y (2011) Characteristics and mechanisms of hexavalent chromium removal by biochar from sugar beet tailing. J Hazard Mater 190: 909-915.

39. Shen X, Huang DY, Ren XF, et al. (2016) Phytoavailability of Cd and $\mathrm{Pb}$ in crop straw biochar-amended soil is related to the heavy metal content of both biochar and soil. J Environ Manage 168: 245-251. 